\title{
Logística para agregados (brita e areia) em grandes centros urbanos
}

\author{
Logistics for aggregates (gravel and sand) \\ in large urban centers
}

\section{Alberto de Barros Aguirre \\ Dr., Departamento de Engenharia de Minas e de Petróleo da Escola Politécnica da Universidade de São Paulo E-mail:abaguirr@terra.com.br}

\section{Wildor Theodoro Hennies}

Prof. Dr.,

Departamento de Engenharia de Minas e de Petróleo da Escola Politécnica da Universidade de São Paulo E-mail:wildorth@usp.br

\section{Resumo}

Uma das necessidades básicas do ser humano é a habitação. O elemento básico é o concreto, a pedra artificial, que demanda grandes quantidades de agregados como areia e brita. Tanto a areia como as rochas que originam a brita são abundantes na natureza e, por isso, têm baixo valor agregado. Em virtude dessa condição, o custo logístico de transporte do porto de areia e da pedreira até chegar ao local de sua utilização onera, significativamente, o seu preço final. Medidas restritivas adotadas, nos grandes centros urbanos, como a proibição de circulação dos veículos de carga em determinadas áreas, horários preestabelecidos, rodízio municipal e especificação de tipos e tamanhos dos veículos, provocam a necessidade de uma frota maior e mais diversificada, além de maior quantidade pessoal.

Palavras-chave: Areia, brita, economia mineral, logística, ordenamento territorial, planejamento urbano, transporte.

\section{Abstract}

One of the human being's basic needs is housing. In Brazil, the basic element for this is concrete, artificial stone, which demands a great amount of aggregates, such as sand and gravel. The sand and rocks are abundant in nature and gravel can be produced at low cost. However, transportation to the area of product utilization can be an incremental factor in the final cost logistics. Both sand and gravel have expressive price variations, which are not necessarily related to mining activities, but to logistic activities, mainly their distribution. Restrictive measures adopted in large urban centers, such as prohibition of hauling trucks in certain areas or during certain hours, alternate license plate end number system (even number plate ending can circulate on even-numbered days and visa versa), and axle-control, generate a need for a larger and more diversified fleet, not to mention more employees.

Keywords: Sand, gravel, mineral economy, logistic, territorial order, urban planning, transportation. 


\section{Introdução Produção e estocagem de areia e brita}

As necessidades de construção civil, em grandes centros urbanos, continuam com crescimento constante. $\mathrm{O}$ déficit habitacional, as ampliações e reformas de escolas, hospitais, grandes centros comerciais, ampliação da rede viária, entre outros, demandam quantidades de agregados da construção, basicamente a areia e a brita, cada vez maiores.

A pedreira e os portos de areia são um caso particular de escavação a céu aberto, estando associados à natureza do produto explotado, o qual é usado sem transformações químicas (Hennies, 2005).

Como toda atividade de mineração, a explotação de uma pedreira ou porto de areia envolve gastos financeiros enormes, em função da soma dos pesados investimentos em equipamentos e instalações e as dificuldades envolvendo as inúmeras atividades para sua extração e beneficiamento.

Em consequência disto, o volume de operação necessita estar em nível elevado para otimizar a utilização dos equipamentos, garantir alta produtividade e a sobrevivência do empreendimento, além do retorno do investimento.

\section{Logística}

Logística é a administração do fluxo de bens e serviços das organizações, orientadas ou não para lucro. É um assunto vital e, frequentemente, absorve parte substancial do orçamento operacional da empresa. Suas atividades típicas incluem o transporte, gestão de estoques, processamento de pedidos, suprimento, armazenagem, manuseio de materiais, embalagem, programação de produção e a administração de materiais (Ballou, 1993).

A Logística analisa a combinação dos gastos com transporte e armazenagem, balanceando no menor custo compatível com a qualidade desejada no atendimento aos clientes.

Os gastos com armazenagem, sinteticamente, são:

- O espaço físico ocupado pelo estoque.

- A mão-de-obra direta envolvida na sua movimentação.

- Os equipamentos de movimentação e armazenagem.

- As instalações físicas.

E os gastos com transporte são:

- Rodagem dos veículos próprios.

- Fretes, quando utilizados terceiros, como carreteiros e empresas transportadoras.

- Equipamentos de carga e descarga.

- Pessoal envolvido.
Para melhor aproveitamento dos equipamentos e instalações, são feitos estoques desses diversos produtos de venda que, com aplicação de princípios logísticos, como a gestão de volume de estoques mínimos e máximos, vão minimizar o valor do capital imobilizado com equipamentos.

A reposição contínua desses estoques pelas vendas realizadas garante rapidez no atendimento aos clientes.

A rapidez nesse atendimento realimenta o fluxo de vendas, traz satisfação e fideliza clientes.

Pelos conceitos logísticos, estoques servem para garantir a disponibilidade de produtos aos clientes, ao longo do tempo.

Quantos produtos serão necessários representa o desafio fundamental da logística, que pode ser dimensionado utilizando:

- A previsão de vendas que fornece os números iniciais.

- Os históricos do mercado e da empresa que vão revelar tendências.

- As ações comerciais e de marketing, que são os filtros para os eventuais ajustes nos dados disponíveis.

- A concorrência que força correções e melhorias contínuas.

- As condições econômicas desfavoráveis, que interferem, diretamente, no decréscimo das vendas.

- As condições econômicas favoráveis, que provocam incremento das vendas.

\section{Transportes}

O transporte é necessário sempre que o local de origem é diferente do local de consumo ou destino. Em mineração, esse conceito é muito forte, devido às ocorrências das rochas e minérios se darem pelo capricho da natureza e não como na maioria dos outros empreendimentos econômicos em que o local de sua instalação é definido através de estudos matemáticos, financeiros e de planejamento estratégico. Daí, os gastos com transportes serem os mais significativos e merecedores de especial atenção.

Ressalta Ballou (1993) que os modais de transporte ideais para o deslocamento de minerais de baixo valor agregado são, preferencialmente, pelo seu custo, o hidroviário e o ferroviário. O rodoviário tem a seu favor, unicamente, a flexibilidade do serviço porta-a-porta e seu emprego deve estar focado na complementação dos demais modais.

\section{Materiais e métodos Conceito de custos}

Segundo Bernardi (2004), é importante diferenciar os gastos, termo empregado no sentido genérico, de despesas e custos. 
Custos são os gastos que estão diretamente relacionados com a atividade-fim de um negócio, como, por exemplo, matérias-primas, embalagens, mão-de-obra direta.

Despesas são os gastos que não estão relacionados diretamente com a atividade-fim, mas são fundamentais para que a empresa e o negócio funcionem, como, por exemplo, aluguel, telefone, material de escritório.

Além da distinção dos custos e despesas, precisa-se diferenciar os gastos fixos e variáveis. Segundo Assef (1997), consideram-se, como gastos fixos, aqueles que não variam, independentemente do nível da atividade da empresa, ou seja, produzindo ou vendendo qualquer quantidade, ou mesmo nada, esses gastos existirão, como, por exemplo, aluguel, salários de mensalistas, depreciações.

Evidentemente esses gastos oscilam ao longo do tempo em função de ajustes na estrutura de pessoal, na racionalização administrativa e por outros fatores que impliquem alteração para maior ou para menor da estrutura da empresa, como aquisição de ativos.

Gastos variáveis são aqueles que estão diretamente relacionados com o nível das atividades da empresa como produção ou vendas. Quanto mais se produz ou se vende, maiores serão os gastos variáveis, como, por exemplo, insumos, energia, comissões sobre as vendas.

\section{Custos no transporte rodoviário}

Para se calcular o custo da distribuição dos agregados na cidade de São Paulo, a exemplo de outros grandes centros urbanos, necessita-se elaborar planilhas de custos, para se obterem os valores para cada tipo de veículo empregado. Os custos relacionados com a atividade de transportes são divididos em dois grandes grupos, os custos fixos e os variáveis.

Custos fixos são os que independem do volume da utilização e estão relacionados com o veículo, pessoal ou licenciamento, como:

\section{- Veículo:}

- Valor de compra do chassi, descontado o valor dos pneus, que são considerados nos custos variáveis.

- Valor de compra da carroceria ou da carreta, esta, idem quanto aos pneus.

- Valor dos equipamentos instalados, como rastreador.

- Vida útil gerencial considerada em meses, para cálculo da amortização.

- Valor residual, para cálculo da amortização.

\section{- Pessoal direto:}

- Salário nominal do motorista e, eventualmente, de ajudante.

- Encargos sociais, que, atualmente, se situam na faixa dos $100 \%$ do salário nominal.
- Seguros: basicamente é feito apenas o de responsabilidade civil para cobrir os danos materiais e pessoais para terceiros.

- Licenciamento:

- IPVA.

- Taxas de licenciamento.

- Seguro obrigatório.

Custos variáveis são aqueles que incidem de acordo com a quilometragem percorrida:

- Manutenção: Valor da manutenção mecânica, neste caso adotada a metodologia da durabilidade média de um motor sem necessitar de retífica, para ter o referencial do custo por quilômetro.

\section{- Combustível:}

Preço do óleo diesel por litro.

Rendimento, da relação km/l, em função do tipo e da utilização do veículo.

\section{- Lubrificantes:}

- Óleo do motor.

- Óleo de câmbio e diferencial.

- Preço por litro.

- Capacidades dos respectivos reservatórios.

- Intervalo de trocas.

- Quantidades de litros adicionados para completar o nível dos reservatórios, consumidos entre as trocas.

- Pneus: Considerado o valor de compra dos novos pneus, valor das recapagens e a vida útil total estimada, geralmente em 3 recapagens.

- Lavagem: Valor e periodicidade das lavagens.

\section{Resultados}

Dentro dos agregados, exemplificamos o caso de uma pedreira localizada dentro do perímetro urbano de São Paulo, ou seja, com o menor raio de escoamento, de onde a brita sai por um preço médio de $\mathrm{R} \$ 18,00 / \mathrm{m}^{3}$ e o frete, a $\mathrm{R} \$ 0,09 / \mathrm{m}^{3} / \mathrm{km}$, até os grandes distribuidores, em valores de outubro de 2005.

A areia e a brita saem da distribuidora para o revendedor de material de construção a um preço médio de:

- Para um revendedor de grande porte a $\mathrm{R} \$ 25,00 / \mathrm{m}^{3}$ e o frete, $\mathrm{R} \$ 0,33 / \mathrm{m}^{3} / \mathrm{km}$, com carretas.

- Para um revendedor de médio porte a $\mathrm{R} \$ 26,00 / \mathrm{m}^{3}$ e o frete, $\mathrm{R} \$ 0,40 / \mathrm{m}^{3} / \mathrm{km}$, com caminhões truck. 
- Para um revendedor de pequeno porte a $\mathrm{R} \$ 30,00 / \mathrm{m}^{3}$ e o frete, $\mathrm{R} \$ 0,47 / \mathrm{m}^{3} / \mathrm{km}$, com caminhões toco.

A brita sai do revendedor a um preço médio de $\mathrm{R} \$ 48,00 / \mathrm{m}^{3}$, para o cliente final, e o frete, a $\mathrm{R} \$ 3,00$, até um raio de $5 \mathrm{~km}$, sendo a base de cálculo $\mathrm{R} \$ 1,00 / \mathrm{m}^{3} / \mathrm{km}$.

Tomando como base um raio de $15 \mathrm{~km}$, os custos chegam:

- A partir dessa pedreira, à distribuidora a $\mathrm{R} \$ 20,70 / \mathrm{m}^{3}$.

- A partir da distribuidora, sai a:

$\mathrm{R} \$ 34,90 / \mathrm{m}^{3}$ para o cliente grande.

$\mathrm{R} \$ 38,00 / \mathrm{m}^{3}$ para o cliente médio.

$\mathrm{R} \$ 44,10 / \mathrm{m}^{3}$ para o cliente pequeno.

A partir da revendedora de material de construção, os custos podem chegar ao cliente final a $\mathrm{R} \$ 63,00 / \mathrm{m}^{3}$, se este não comprar mais nada e, portanto, não diluir o frete com outros produtos.

\section{Discussão}

Cada um de nós, pela manhã, utilizaremos, no mínimo, um sistema de transporte, para atividades cotidianas como ir ao mercado ou ir para o trabalho.

A expansão urbana, nos grandes centros, acaba, geralmente, expulsando atividades exploratórias para privilegiar a habitação. Esta, muita das vezes, é realizada de forma não planejada. Também a instalação de indústrias afastam as atividades exploratórias dos centros urbanos. Tudo isso resulta no distanciamento das fontes, fato que acarreta maiores custos de transporte, mais consumo de energia e mais congestionamentos de trânsito. Essa problemática leva, ainda, a um aumento da poluição atmosférica.

Aliado ao fato de a matriz de transporte, na cidade de São Paulo, ser baseada no modal rodoviário, há, ainda, falta de planejamento e investimento em outros modais como o ferroviário ou hidroviário.

É interessante lembrar de que uma boa parte das exportações é realizada através do porto de Santos, mercadorias essas que, oriundas do interior do Estado e de outros Estados, obrigatoriamente passam pela cidade de São Paulo, congestionando suas principais vias de acesso pela ainda não completada obra do rodoanel viário.

Em 1997, na tentativa de reduzir a poluição e congestionamentos, a Prefeitura do Município de São Paulo implantou o VUC, o Veículo Urbano de Carga, o rodízio municipal, e as três Zonas Máximas de Restrição à Circulação (ZMRs), que só podem ser abastecidas pelos VUCs, que têm 5,50 metros de comprimento entre pára-choques. A operação de entregas pode se repetir várias vezes ao longo do dia, pelas suas reduzidas dimensões, ou seja, o VUC causa um aumento na quantidade de viagens na cidade.
A restrição da circulação de caminhões dentro do minianel viário fez com que a idade média da frota da capital sofresse uma elevação de cinco anos, saltando de 17, mesmo número da média nacional, para 22 anos, em função da necessidade das transportadoras de manterem ou comprarem veículos mais velhos para substituir aqueles que, em função do número final da placa, estão barrados no dia do rodízio (Reis, 2001).

\section{Caminhões $\times$ Congestionamentos}

Cerca de 210 mil caminhões trafegam diariamente pela cidade de São Paulo, concentrando a circulação nas Marginais Tietê e Pinheiros (com 82 e 48 mil veículos, respectivamente) e a Avenida dos Bandeirantes (com 29 mil veículos). Nos últimos 28 anos, a malha viária da cidade cresceu apenas 2.500 quilômetros, passando para 15.500 quilômetros, o que, de fato, é muito pouco, resultando num aumento significativo dos congestionamentos, que passou de $40 \mathrm{~km}$ no horário de pico da tarde para $120 \mathrm{~km}$ (Scaringella, 2004).

\section{Conclusão}

Com o crescimento da cidade, as pedreiras cederam lugar à chegada dos novos habitantes, passando a operar em lugares mais distantes. E os portos de areia exauriram suas reservas. Como consequência direta, aumentam os custos de transporte do local de origem para os locais de destino, o trânsito, congestionamentos e poluição ambiental.

A falta de planejamento e a falta de investimento na infra-estrutura viária aliadas à adoção de medidas paliativas, para minimizar os congestionamentos de trânsito e a poluição, resultam numa eficácia bastante reduzida, uma vez que não se combatem ou não se resolvem as causas do problema. Uma das medidas cogitadas e ainda não implantada é a cobrança de pedágio nas marginais.

As atividades de mineração exigem elevadas somas de dinheiro em investimento de equipamentos, instalações, pessoal especializado e não há retorno imediato. É difícil a implantação de medidas para se reduzirem os custo, tendo-se, ainda, de aumentar a escala de produção. Apenas a exploração do negócio pode trazer o retorno do investimento feito.

A areia mais apreciada tem origem no vale do Rio Paraíba do Sul, distante $90 \mathrm{~km}$ da capital. Assim, há os consequentes aumentos de custos de transporte. Em função desse incremento, a areia de brita vai tendo maior aceitação no mercado.

Portanto é imperativo que, tanto os portos de areia, como as pedreiras se situem o mais perto possível de seus locais de consumo, preferencialmente dentro do perímetro urbano. Isso é possível com um planejamento do uso e ocupação do solo, com zonas específicas, definidas por parte da administração municipal. 
É prioritário buscar fórmulas que agilizem e, ao mesmo tempo, reduzam custos logísticos, evitando transbordos e toda operação que agregue somente custos.

Para se chegar ao cliente final, desde que não seja grande consumidor, não há como empregar somente uma modalidade de transporte. Haverá, então, algum transbordo da carreta da saída do porto ou pedreira para algum veículo de menor porte. É este que chegará ao cliente final.

Não se pode decidir a melhor maneira de entrega somente pelo custo do modal de transporte, mas deve-se considerar o local, o horário, o volume da carga, enfim avaliar as várias peculiaridades que envolvem o processo. Por fim, tem-se de observar as restrições ao tráfego de veículos de carga em vigor.

Quando os custos com o transporte atingem o valor da brita e dobram o preço de venda?

Considerando a capacidade de carga dos veículos:

Carreta distribuição (30 t) 76 km

Caminhão truck (12 t) 65 km

Caminhão toco (6 t) $64 \mathrm{~km}$

VUC $\quad(2,5 \mathrm{t}) \quad 48 \mathrm{~km}$

Portanto o desafio da Logística é compor um sistema de distribuição para que os agregados cheguem ao cliente final, distribuidor, revendedor ou obra, ao menor custo e que esse custo seja compatível com a necessidade do cliente. Algumas ações:

- Aplicar transbordos para reduzir, ao mínimo, o deslocamento com veículos menores.

- Dispor de áreas para transbordo e estocagem, em áreas de corredores de tráfego.
- Dimensionar a frota quanto a tipos e quantidades de veículos.

- Escalonar os horários, para o melhor atendimento possível.

- Buscar a maior integração fornecedor - cliente para redução de custos e tempo.

- Estudar a viabilidade de incrementar entregas diretas da pedreira, para se evitarem estoques e transbordos.

Em função de menores custos logísticos, empreender processo de competitividade, pois:

- O desafio é grande.

- As possibilidades são muitas.

- A exigência dos clientes é muito grande.

\section{Referências bibliográficas}

ASSEF, R. Guia prático de formação de preços: aspectos mercadológicos, tributários e financeiros para pequenas $e$ médias empresas. Rio de Janeiro: Campus, 1997. 136p.

BALLOU, R. H. Logística empresarial: transportes, administração de materiais e distribuição física. Tradução de Hugo T. Y. Yoshizaki. São Paulo: Atlas, 1993. 388p.

BERNARDI, L. A. Manual de formação de preços: políticas, estratégias e fundamentos. (3. ed.) São Paulo: Atlas, 2004. 280p.

HENNIES, W.T. et al. Pedras e pedreiras: fundamentos. Revista Brasil Mineral, São Paulo, n. 238, p. 64-70, maio 2005.

REIS, N. G. Custos operacionais fretes e renovação de frotas. (Atualizado em agosto 2001). Disponível em: <http://www. guiadotrc.com.br/pdfiles/manualdecusteio.pdf $>$. Acesso em: 14 nov 2005.

SCARINGELLA, R. S. A crise da mobilidade urbana em São Paulo. (2004). disponível em: http://www.scaringella-transito.com.br/ body_opiniao_015.html. Acesso em 15 nov 2005.

Artigo recebido em 03/08/2009 e aprovado em 06/04/2010

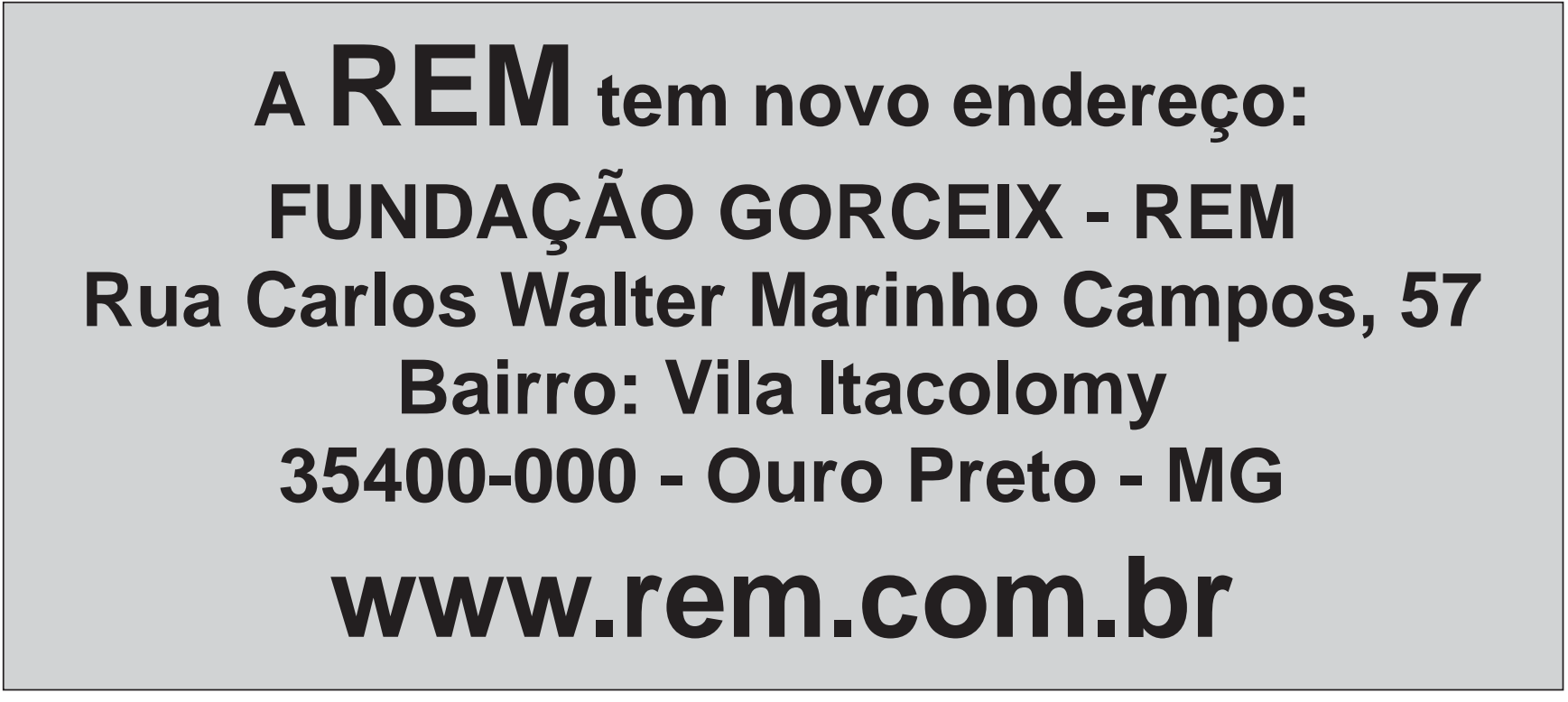

